\title{
Projected Changes of Grassland Productivity along the Representative Concentration Pathways during 2010-2050 in China
}

\author{
Feng Wu, ${ }^{1}$ Xiangzheng Deng, ${ }^{2,3}$ Fang Yin, ${ }^{2,3}$ and Yongwei Yuan ${ }^{4}$ \\ ${ }^{1}$ State Key Laboratory of Water Environment Simulation, School of Environment, Beijing Normal University, Beijing 100875, China \\ ${ }^{2}$ Institute of Geographic Science and Natural Resource Research, CAS, Beijing 100101, China \\ ${ }^{3}$ Center for Chinese Agricultural Policy, CAS, Beijing 100101, China \\ ${ }^{4}$ Faculty of Resources and Environmental Science, Hubei University, Wuhan 430062, China
}

Correspondence should be addressed to Xiangzheng Deng; dengxz.ccap@igsnrr.ac.cn

Received 17 May 2013; Accepted 12 July 2013

Academic Editor: Hongbo Su

Copyright (C) 2013 Feng Wu et al. This is an open access article distributed under the Creative Commons Attribution License, which permits unrestricted use, distribution, and reproduction in any medium, provided the original work is properly cited.

\begin{abstract}
The grassland is an important land use type that plays an important role in the ecosystem services supply in China. It is of great significance to the grassland management to determine the changing trend of grassland productivity and its response to climate change. Firstly, the relationship between grassland productivity and climate change, geographical conditions, and human activities was analyzed with the panel data of the whole China during 1980-2010 in this study. The result indicated that the temperature and precipitation were very important to grassland productivity at the national scale. Secondly, the grassland in China was divided into 7 grassland ecological-economic zones according to the ecosystem service function and climate characteristics. The relationship between grassland productivity and climate change was further analyzed at the regional scale. The result indicated that the temperature is more beneficial to the increase of the grassland productivity in the Qinghai-Tibet Plateau and the Southwest Karst shrubland region. Thirdly, the increase of the temperature and precipitation can increase the grassland productivity and consequently relieve the pressure according to the climate factors of simulation with the community climate system model v4.0 (CCSM). However, the simulation result indicates that the human pressure on grasslands is still severe under the four RCPs scenarios and the grassland area would reduce sharply due to the conversion from the grassland to the cultivated land. What is more, there is still a great challenge to the increase of total grassland productivity in China.
\end{abstract}

\section{Introduction}

The grassland is one of the most important land use types in China due to its essential functions in the development of the animal husbandry and the supply of ecosystem services. Grassland is a multifunctional ecosystem, which can provide important ecological benefits as well as economic benefits. Traditionally, grasslands provide a broad range of agronomic services, including the provision of forage, milk, meat, wool and pelts. The grassland ecosystem of China plays an important role in promoting the regional economic development, protecting the ecological environment and conserving the biodiversity [1]. The grassland of China is about 400 million hectares, accounting for about $41.7 \%$ of the national total land area [2]. The grassland area of China is only second to that of
Australia in the world. However, the grassland productivity level of China is much lower than that in other parts of the world [3]. Besides, the extreme climate shifts and the increasing demand for meat due to the rapid population growth have put tremendous pressure on the grassland productivity. Some recent studies show that the grassland productivity is sensitive to the climate change, especially in the InnerMongolian Plateau, Qinghai-Tibet Plateau, and Northwest of China [4-6]. The change of precipitation regimes has profound impacts on the grassland productivity, especially in the arid and semiarid regions characterized by the limited water $[7,8]$. In the temperate grasslands, the interannual variability of the total precipitation is the primary climatic factor that causes fluctuations in the grassland productivity [9-12]. The combined effects of the land use and climate 
TABLE 1: Summary of the variables used in this study.

\begin{tabular}{|c|c|c|c|c|c|}
\hline Variable & County number & Max & Mean & Min & Description \\
\hline NPP & 1669 & 1386 & 439 & 1.07 & $\mathrm{gc} / \mathrm{m}^{2}$, net primary productivity \\
\hline $\mathrm{Ta}$ & 1669 & 25.55 & 12.60 & -4.81 & ${ }^{\circ} \mathrm{C}$, temperature \\
\hline Rain & 1669 & 2846 & 926.90 & 19.46 & Mm, precipitation \\
\hline Sun & 1669 & 975.97 & 762.64 & 475.66 & Hour, sunshine duration \\
\hline Soil_n & 1669 & 0.96 & 0.25 & 0.05 & Percentage of soil $n$ \\
\hline Soil_p & 1669 & 0.25 & 0.13 & 0.02 & Percentage of soil $\mathrm{p}$ \\
\hline Dem & 1669 & 2832 & 732 & 128 & Meter, elevation \\
\hline Splain & 1669 & 0.42 & 0.28 & 0.01 & Percentage of plain area \\
\hline pop & 1669 & 179 & 43 & 2 & Ten thousand people, Population \\
\hline Gdp1 & 1669 & 1.53 & 0.18 & 0.05 & Percentage of GDP of the primary industry \\
\hline Meat & 1669 & 14670 & 3850 & 650 & Ton, beef, and mutton \\
\hline
\end{tabular}

change further complicate the underlying change of the grassland productivity [13-16]. It is necessary to explore the coupling effects of the land use management and climate change on the grassland productivity so as to carry out the adaptive management to mitigate the climate change [17-19].

The grassland productivity, integrating both the fodder quality and yield level, is an important index to represent the ability of the grasslands to meet the needs of the livestock sector and the pastoral societies. It is critical to the management and planning of the grassland resources to better understand the relationship between the grassland productivity and the possible climate change scenarios, especially with regard to the livestock development $[20,21]$. The grassland productivity can directly reflect the production capacity of the grassland in the natural environment. Besides, the grassland productivity is influenced by various factors, including the internal factors of the grassland ecosystem such as the soil, grassland area and livestock, and the external factors such as the labor input and climate change. The Intergovernmental Panel on Climate Change (IPCC) for the fifth assessment report updated the scenario development from the SRES to a new set of integrated scenarios, the representative concentration pathways (RCPs), analyzed the advantages of the new approaches of scenarios development, and depicted the characteristics of the identified four representative concentration pathways (RCP8.5, RCP6, RCP4.5, and RCP3-PD). These schedules of radiative forcing, greenhouse gas emission, concentration and land use in every roadmap were proposed based on the four models including MESSAGE, AIM, MiniCAM, and IMAGE. It is of great significance to understand the changes of grassland productivity along the representative concentration pathways during 2010-2050 in China.

The grassland is widely distributed and shows great regional difference in China. The grasslands in China can be divided into 7 grassland ecological-economic regions according to the ecological conditions, moisture and temperature, grassland types, grassland production, and consistence between the grassland systems and economic systems [22, 23]. It is necessary to manage the grassland by ecologicaleconomic region under the condition of land use change and climate change. The main changing trend of climate change in each grassland ecological-economic region can provide a basis for taking management measures to relieve the pressure from the climate change. But almost all the previous literatures were focusing on how and how much climate change had affected grassland. For example, Yu et al. [24] analyzed grassland activity by evaluating remotely sensed Normalized Difference Vegetation Index (NDVI) data collected at 15-day intervals between 1982 and 2006 and found that vegetation on the Tibetan Plateau is unable to exploit additional thermal resources availed by climate change. $\mathrm{Ni}$ [25] found that the numbers of $\mathrm{C}_{3}$ species, $\mathrm{C}_{4}$ species, grasses, and forbs had positive relationship with precipitation and aridity. On a regional basis, the combined effect of precipitation and temperature, the aridity, is more significantly correlated with the distribution of $\mathrm{C}_{3}$ species and forbs, which are more dominant than with $\mathrm{C}_{4}$ species, grasses and succulents in the study area. Su et al. [26] analyzed the changes of temperature, precipitation and climatic productivity of grasslands in Ningxia farming-pasturing ecotone based on the meteorological data from 1954 to 2004 and found that grassland productivity will increase by $10 \%$ to $20 \%$ if the annual temperature increases by $1^{\circ} \mathrm{C}$ to $2^{\circ} \mathrm{C}$ and the annual precipitation increase by $10 \%$ to $20 \%$ in the future. It is of great reference value to the reasonable development of grassland resources and the research of terrestrial ecosystem carbon cycle to accurately estimate the grassland productivity in China.

\section{Data and Materials}

This study analyzed the changes of the climate and grassland productivity from 1980 to 2010 with the correlation analysis. A series of data were collected, including the grid data of NPP, soil nitrogen and phosphorus, DEM, the percent of plain area at the county level involving 1669 counties, which is the level of the census data such as the population, GDP, and meat (Table 1). Then a panel dataset was constructed with the data of six periods, including 1985, 1990, 1995, 2000, 2005, and 2010. This study analyzed the contribution of the climate change to the change of the grassland productivity on the basis of the dataset at the national and regional ecologicaleconomic scales. The final part discusses the impacts of the future climate change on the grassland productivity from 
2010 to 2050 on the basis of the GCM simulation output. These analyzed data involved grassland area, grassland productivity, and future climate data.

2.1. Grassland Data. The grassland data were extracted from the land use database developed by the Chinese Academy of Sciences (CAS). The data were originally derived from 512 remotely sensed images with a spatial resolution of $30 \mathrm{~m} \times$ $30 \mathrm{~m}$, which were provided by the US Landsat TM/ETM satellite. The data of five periods were used in this study, that is, the data of year 1988, 1995, 2000, 2005, and 2010. A hierarchical classification system including 25 land use types was applied to the data. Besides, the data team also spent considerable time validating the interpretation of TM images and land use classifications against the extensive field validation. The field validation indicated that the average interpretation accuracy reached 95\% [27, 28]. The grassland was divided into three kinds, that is, the dense grass, moderate grass and sparse grass. The grassland of china is mainly distributed along the Great Wall in Inner Mongolia, and in the region of Gansu and Xinjiang, the Tibetan Plateau and the Loess Plateau (Figure 1). The grassland area from the land use dataset is about 346 million hectares, which is smaller than that from the comprehensive and systematic grassland surveys due to the difference of the grassland classification system.

2.2. Grassland Productivity. The grassland productivity data were derived from the regional census statistics and remotely sensed images. The regional census statistics provide the aggregated data that are collected by county. However, the statistic data also have many disadvantages. For example, they are limited by the relatively coarse spatial resolution within the administrative units, gaps in time series and difference of the data collection methods among counties. By contrast, the data derived from the remotely sensed images have a higher temporal continuity and higher spatial resolution. NPP is used as the indicator of the grassland productivity since it plays a key role in the vegetation growth and is closely related to the yield of the grassland. NPP was estimated with the efficiency model on the basis of the ground observation data of meteorological stations, soil quality data, and land use data [29-31]. Besides, the vegetation greenness observation data from the AVHRR and the light use efficiency model of the MODIS were used in the estimation of NPP. A simple light use efficiency model (MOD17) is at the core of the algorithm of NPP, and it requires daily inputs of incoming photosynthetic active radiation (PAR), minimum temperature over the period of 24 hours, and average vapor pressure deficit in the daytime. The NPP data during 19851999 came from the remote sensing data of NOAA/AVHRR, and that during 2000-2010 came from the NPP product of MODIS in the study.

2.3. Meteorological Data and Future Climate Change Scenario. The projected climate data from 2006 to 2050, including the average daily temperature, precipitation, absolute minimum temperature and daily maximum and minimum temperatures, come from the datasets of CCSM simulation.

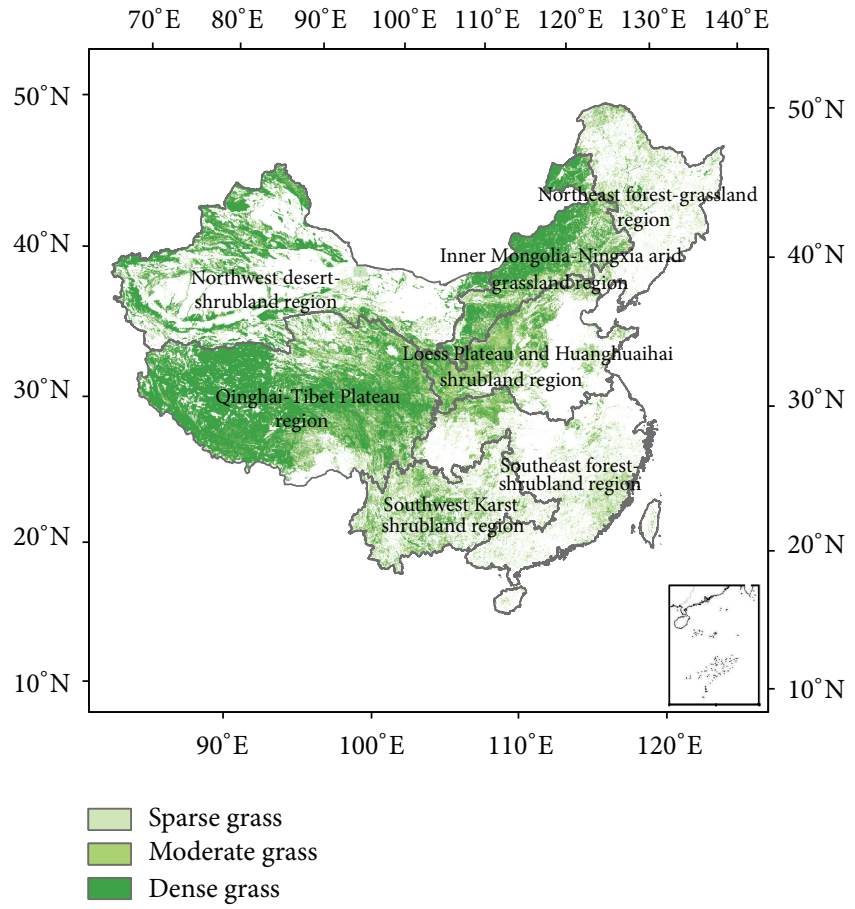

Figure 1: The Grassland distribution over grassland ecologicaleconomic regions of China in year 2005.

The Cancún agreements state that the future global temperature rise should be limited to below $2.0^{\circ} \mathrm{C}(3.6 \mathrm{~F})$ in comparison to the preindustrial level in 2100 [32]. The low concentration pathway of RCP3-PD has attracted the attention of international research community among RCP8.5, RCP6, RCP4.5 and RCP3-PD since the temperature rise is approaching the $2.0^{\circ} \mathrm{C}$ goal under this scenario [33]. These scenarios describe a world in which great emphasis is put on local solutions to economic, social, and environmental sustainability. The data of the future climate change from 2011 to 2050 were obtained by the simulation with the CCSM model. The future climate data from 2011 to 2050 can be corrected through overlying the future climate change data and historical meteorological data from 2006 to 2010.

The historical meteorological data, including the annual temperature and annual precipitation from 1980 to 2010, were acquired from China Meteorological Bureau, and were interpolated into the $1 \mathrm{~km} \times 1 \mathrm{~km}$ grid data with the Kriging algorithm and modified with the DEM data. The data of the future climate come from the scenario data of the representative concentration pathways (RCPs), which were adopted by the fifth assessment report of IPCC, including four scenarios, the radiative forcing of which ranges from $2.6 \mathrm{~W} / \mathrm{m}^{2}$ to $8.5 \mathrm{~W} / \mathrm{m}^{2}$. The data of the four RCPs scenarios are the product of an innovative collaboration among the assessment modelers, climate modelers, terrestrial ecosystem modelers, and emission inventory experts. These four RCPs scenarios provide the global dataset of land use and greenhouse gas emission for the period extending to 2100, with the spatial resolution of 0.5 degree $\times 0.5$ degree. 


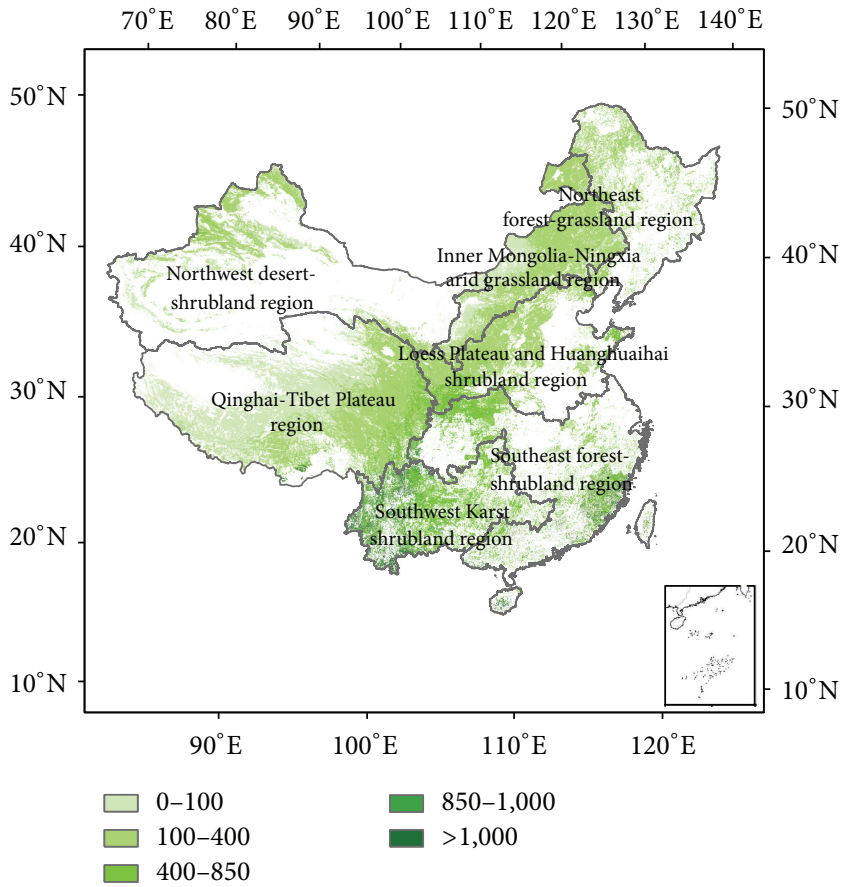

Figure 2: The spatial distribution of grassland productivity over china in the year of 2010 .

\section{Method}

The characteristics of the spatial distribution and seasonal change of the grassland NPP are as follows. The annual total and average grassland NPP in China in year 2010 were $6.8 \times 10^{9} \mathrm{gC} /$ year and $490 \mathrm{gC} / \mathrm{m}^{2} /$ year, respectively. There was significant regional heterogeneity of the grassland productivity. The grassland NPP in the east part was higher than that in the west part, and it was higher in the south part than in the north part. On the whole, it increases from Northwest China toward Southeast China except Tibetan Plateau (Figure 2). On the whole, the grassland NPP increases with the longitude and decreases with the latitude although there are some fluctuations. The characteristic of longitude zonation of grassland NPP is highly correlated with the longitudinal variability of the climate. The climate becomes more favorable for the vegetation growth as the latitude decreases. The grassland productivity of Southwest karst shrub land region is the highest among these regions, reaching about $1000 \mathrm{gC} / \mathrm{m}^{2}$ in year 2010 .

In this study, we unified these data of different spatial scales and converted the data at the grid scale into the county scale so as to identify the reasons for the regional heterogeneity of the grassland productivity and analyze the impacts of geographical factors, climate and human activities on the grassland productivity. It is scarcely possible to establish model in property of mechanism due to the complex relationships between grassland productivity and climate change as well as social and economic activities and geographical factors. In this condition, the econometric model becomes an alternative choice. This kind of model is increasingly applied
TABLE 2: Analysis of impacts of influencing factors on NPP based on the econometric model.

\begin{tabular}{|c|c|c|c|c|}
\hline \multicolumn{5}{|c|}{ Dependent variable: $\log (\mathrm{NPP})$} \\
\hline & Model-I & Model-II & Model-III & Model-IV \\
\hline $\log (\mathrm{ta})$ & $\begin{array}{c}0.035^{* * *} \\
(-11.54)\end{array}$ & $\begin{array}{c}0.026^{* * *} \\
(-8.12)\end{array}$ & $\begin{array}{c}-0.022^{* * *} \\
(-8.03)\end{array}$ & $\begin{array}{c}-0.035^{* * *} \\
(-9.72)\end{array}$ \\
\hline $\log$ (rain) & $\begin{array}{l}0.967^{* * *} \\
(-197.32)\end{array}$ & $\begin{array}{l}0.856^{* * *} \\
(-67.74)\end{array}$ & $\begin{array}{l}0.928^{* * *} \\
(-83.42)\end{array}$ & $\begin{array}{l}0.963^{* * *} \\
(-58.75)\end{array}$ \\
\hline $\log (\operatorname{sun})$ & & $\begin{array}{c}-0.829^{* * *} \\
(-9.48)\end{array}$ & $\begin{array}{l}-0.016 \\
(-0.19)\end{array}$ & $\begin{array}{l}0.169 \\
-1.72\end{array}$ \\
\hline $\log (\mathrm{dem})$ & & & $\begin{array}{c}-1.745^{* * *} \\
(-67.42)\end{array}$ & $\begin{array}{c}-1.803^{* * *} \\
(-54.68)\end{array}$ \\
\hline Soil_n & & & $\begin{array}{c}-0.119^{* * *} \\
(-4.09)\end{array}$ & $\begin{array}{c}0.036 \\
(-1.03)\end{array}$ \\
\hline Soil_p & & & $\begin{array}{c}7.817^{* * *} \\
(-19.8)\end{array}$ & $\begin{array}{l}6.550^{* * *} \\
(-14.05)\end{array}$ \\
\hline Splain & & & $\begin{array}{c}0.026^{* * *} \\
(-4.79)\end{array}$ & $\begin{array}{c}0.025^{* * *} \\
(-3.54)\end{array}$ \\
\hline pop $_{t-1}$ & & & & $\begin{array}{c}0.031^{* * *} \\
(-3.59)\end{array}$ \\
\hline meat $_{t-1}$ & & & & $\begin{array}{l}0.156^{* * *} \\
(-12.73)\end{array}$ \\
\hline $\operatorname{gdp} 1_{t-1}$ & & & & $\begin{array}{c}-0.049^{* * *} \\
(-8.14)\end{array}$ \\
\hline Intercept & $\begin{array}{c}-2.127^{* * *} \\
(-54.03)\end{array}$ & $\begin{array}{c}4.247^{* * *} \\
(-6.31)\end{array}$ & $\begin{array}{l}12.42^{* * *} \\
(-20.04)\end{array}$ & $\begin{array}{l}9.750^{* * *} \\
(-13.06)\end{array}$ \\
\hline Adjusted $R^{2}$ & 0.732 & 0.733 & 0.818 & 0.838 \\
\hline
\end{tabular}

$t$ statistics in parentheses: ${ }^{*} P<0.05,{ }^{* *} P<0.01$, and ${ }^{* * *} P<0.001$.

to explore the relationships between productivity and its driving factors. In this study, we established an econometric model and analyzed the effects of variables at different levels on the grassland productivity.

Since the panel data are repeated observations of the same samples that are nested into the individual objects, we treated the repeated observations as the first level and the individual objects as the second level. Besides, the random factors over time were also introduced into the first level. A series of fixed effect models were established and then compared so as to choose a robust one as the basis model to more accurately analyze impacts of the climate change on the grassland productivity:

$$
\begin{aligned}
\log (\mathrm{npp})_{i t}= & \beta_{0}+\sum_{p=1}^{P} \alpha_{p} X_{p i t}+\sum_{q=1}^{Q} \lambda_{q} E_{q i t} \\
& +\sum_{r=1}^{R} \gamma_{r} Z_{r i t}+\mu_{i}+\varepsilon_{i t},
\end{aligned}
$$

where $X_{\text {pit }}$ refers to the annual average temperature, precipitation, and sunshine duration; $E_{\text {qit }}$ refers to available phosphorus in the soil, available nitrogen in the soil and terrain elevation factor; $Z_{\text {rit }}$ refers to the population, GDP, beef and mutton; $\alpha_{p}, \lambda_{q}$, and $\gamma_{r}$ act as the parameters; $\mu_{i}$ represents the individual factor; $\varepsilon_{i t} \mathrm{~N}\left(0, \sigma_{i}^{2}\right)$ is the composed error. The pool regression model has been chosen here since the fitting accuracy of this model is better than others (including first-difference approach and deviation from means). 


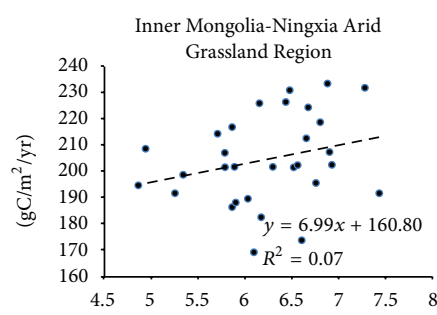

$\left({ }^{\circ} \mathrm{C}\right)$

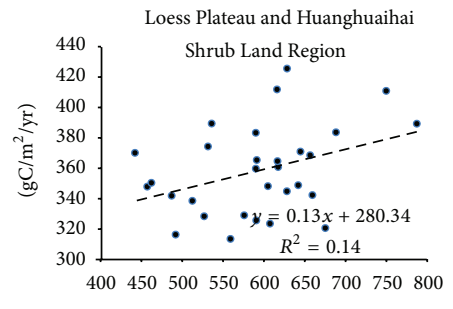

$(\mathrm{Mm})$

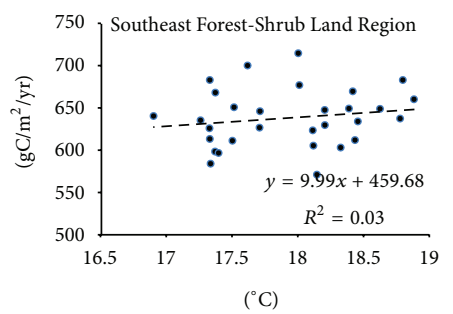

$\left({ }^{\circ} \mathrm{C}\right)$

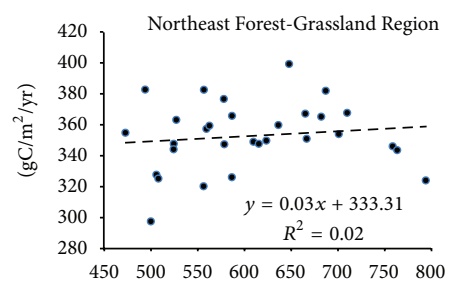

$(\mathrm{Mm})$

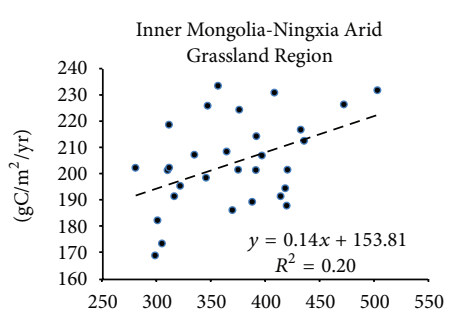

$(\mathrm{Mm})$
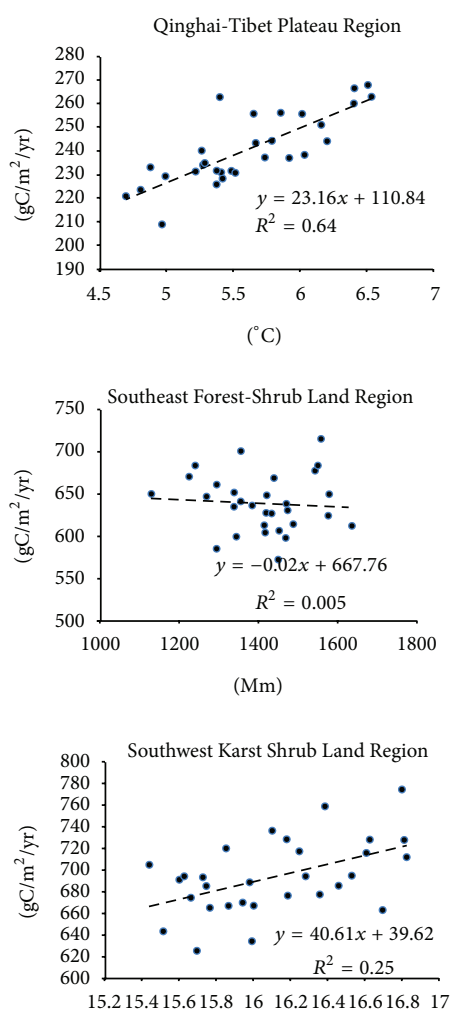

$\left({ }^{\circ} \mathrm{C}\right)$
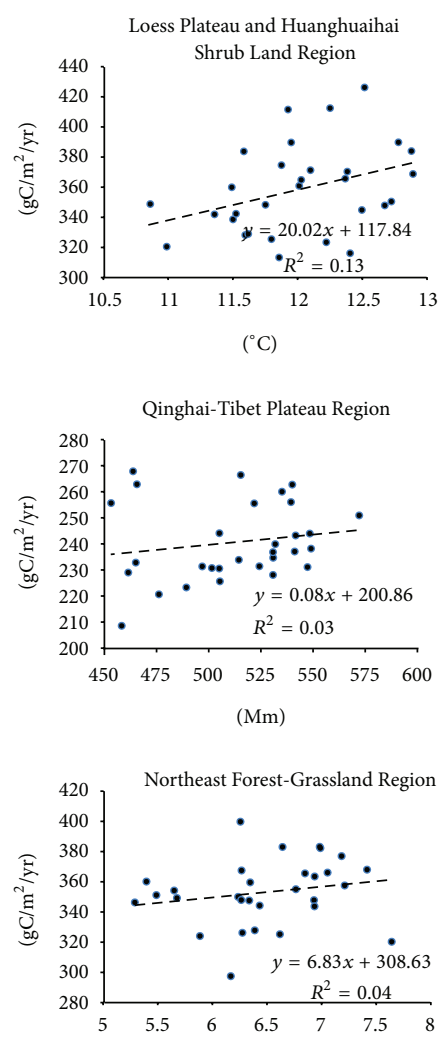

$\left({ }^{\circ} \mathrm{C}\right)$

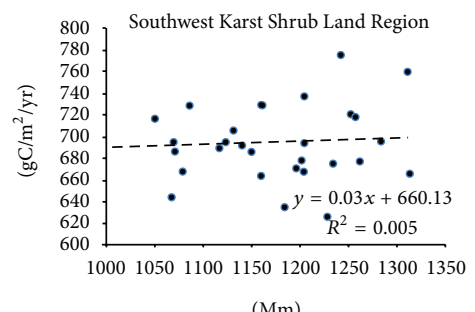

(Mm)

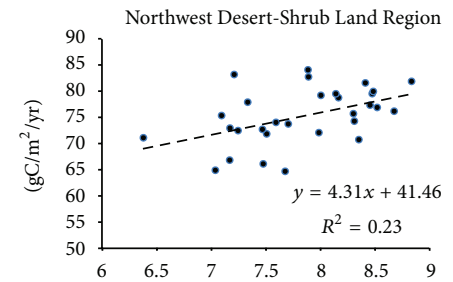

$\left({ }^{\circ} \mathrm{C}\right)$

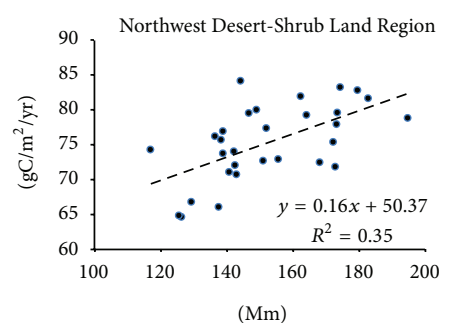

(Mm)

Figure 3: Correlation analysis between the climate index and grassland productivity during 1985-2010 at the grassland ecological-economic zones level.

We analyzed the effects of variables at different level on the grassland productivity by introducing the variables step by step (Table 2).

\section{Results}

4.1. The Relationship between NPP and the Climate Change. As can be seen from the estimation results, the influence of the precipitation and temperature is more significant than that of the sunshine duration. Besides, the elevation has a significant negative impact on NPP, which reflects the character of vertical zones. In addition, the soil phosphorus also has significant positive effects on NPP. What is more, as for the socioeconomic factors, both the population and the demand for meat have significant positive effects on NPP, and more labor will be invested into the management and production of grassland with increase of population and demand for 
meat. The percentage of the primary industry in the total GDP has negative effects on NPP, which demonstrates that the production of primary industry would put more stress on the grassland. The estimation results of the model indicated that the impacts of the geographical factors.

The climatic factors included the temperature, precipitation, and sunshine duration in this study. The result indicated that the precipitation and temperature were closely correlated with NPP at the significant level of $0.1 \%$, with the coefficient of 0.96 and -0.04 , respectively. According to the analysis of the changing trends of temperature and precipitation under the RCPs-PD scenarios, it would be concluded that most of the grassland regions will turn "warm," which will promote the accumulation of dry matter and consequently increase NPP.

As for the physical geographic factors, the increase of the altitude was negatively related with NPP. By contrast, the percent of plain area was positively correlated with NPP. The result showed that the temperature and the precipitation would decrease as the altitude increases, indicating the vertical zonality of vegetation. In addition, the result indicated that the higher levels of the soil nitrogen and phosphorus were more beneficial to the increase of NPP.

Among the regional socioeconomic factors, the population showed a significant correlation with NPP. On the basis of the constantly added variables, the coefficient of the population eventually stabilized at 0.03 (at the significant level of $0.1 \%$ ), suggesting that when population increases by $0.1 \%$, the NPP would drop by $0.03 \%$, which means that population growth will increase labor input and consequently lead to the increase of NPP of the grassland. In fact, the population growth will inevitably increase the input to grassland production and management. What is more, the increasing demand for food and meat may also put more attention on the existing grassland and promote the grassland productivity.

In this study, the regional economic indices, including the percentage of the primary industry in the total GDP, population and the demand for meat, were used to analyze the effects of the regional economic development on the grassland NPP. The result suggests that the coefficient of GDP is -0.05 , which shows that when GDP increases by $0.1 \%$, the pressure on NPP will increase by $0.05 \%$, indicating that the rapid growth of the primary industry can reduce the grassland productivity to a certain extent. In the regions where there is a very low level of social development, the production and living of the people mainly rely on the animal husbandry, and the socioeconomic development greatly depends on the grassland resource. The increase of the economic output will put more pressure on the grassland resource and may consequently lead to the decline of the grassland NPP.

There is an obvious difference in the characteristics of the different grassland ecological-economic regions in China, which greatly influences the grassland productivity. So the ecological-economic region is a suitable unit to analyze the relationship between the grassland productivity and climate. In this study, we analyzed the relationship between temperature, precipitation and NPP at the regional scale with the scatter plots, fitted lines and coefficient of determination R2 (Figure 3). The fitted lines were calculated by OLS in this

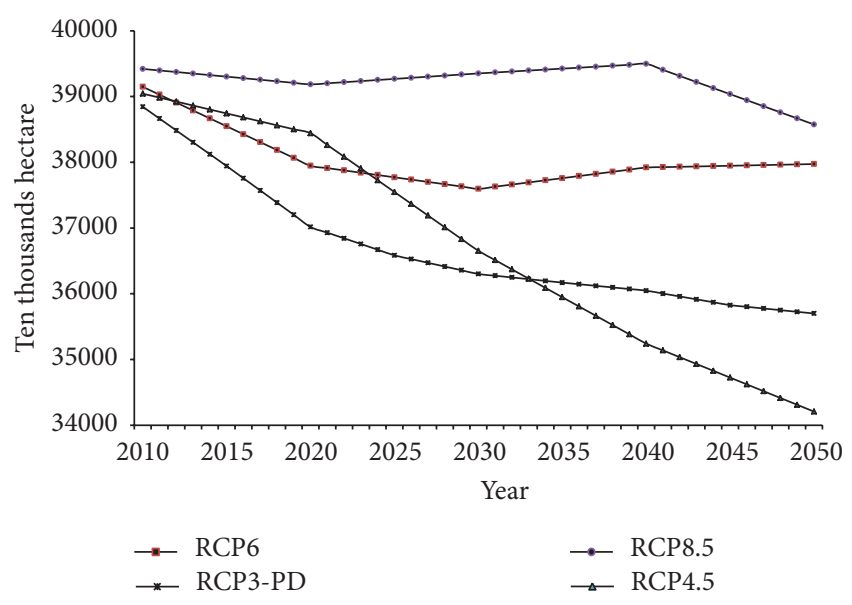

FIGURE 4: Changing trends of the projected grassland area under the RCPs scenarios.

study. The result indicated that NPP has good correlation with the precipitation in the Inner Mongolia-Ningxia arid grassland region. The precipitation plays a dominant role in affecting the grass quality in this region, indicating that the drought may greatly restrict the vegetation growth. Besides, in the Qinghai-Tibet Plateau region, there is a better correlation between temperature and NPP, while the correlation between rainfall and NPP is not very significant. The local climate is the plateau climate in this region, and the low average temperature is the basic factor that restricts the grass growth. In addition, the correlation between temperature, rainfall, and grassland NPP is comparatively better in the northwest desert-shrub region. However, there is less significant correlation between temperature, precipitation and NPP in other four grassland ecological-economic regions (Figure 3), which may be due to the greater impacts of human activities on NPP in these regions.

In summary, according to the annual, monthly and seasonal variations of grassland NPP, the suitable combination of water and thermal factors plays a key role in influencing the grassland productivity. The finding has significant implications for the vegetation succession in the grassland ecosystems with predicted changes in spatial-temporal patterns of precipitation under the influence of global climate change.

4.2. The Analysis of the Future Scenario. This study simulated the future land use under the four scenarios in China (Figure 4). The forecasted future temperature rise in the whole world is controlled within $2^{\circ} \mathrm{C}$ at present, so the result simulated with the MESSAGE model was selected as the first choice for this study. The simulation result using the MESSAGE model indicated that the fluctuation range of the grassland area is very limited, reaching no more than 3.9 million square kilometers. The simulation results show that there would be a downward trend of the grassland area and rising of temperature at $3.2-3.8^{\circ} \mathrm{C}$ in the future, but the area would be around 360 million hectares after year 2025 .

With the improvement of the income level rise and more attention paid to the dietary nutrition balance, China's beef 


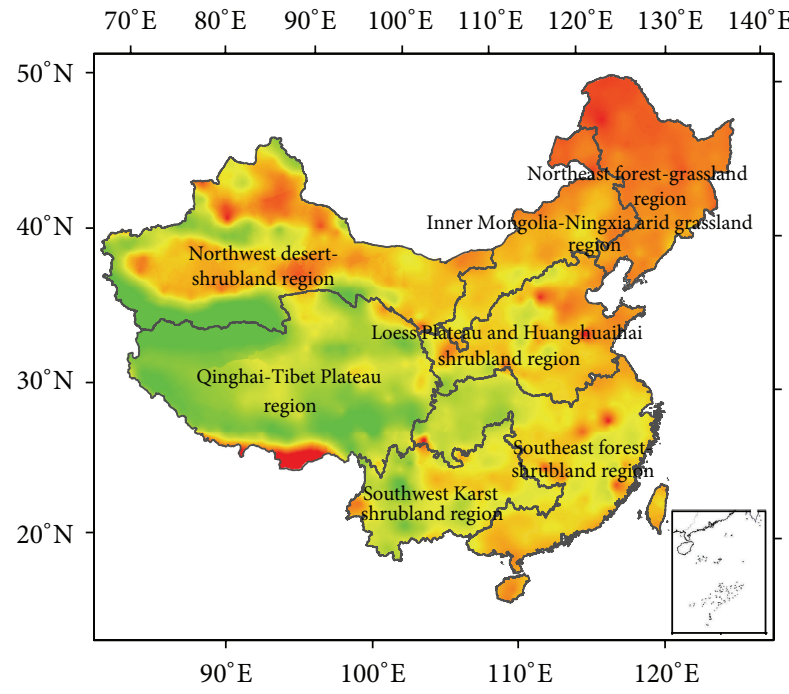

High: 3.2

Low: -3.8

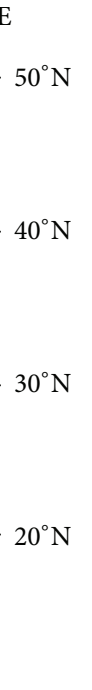

(a) Temperature

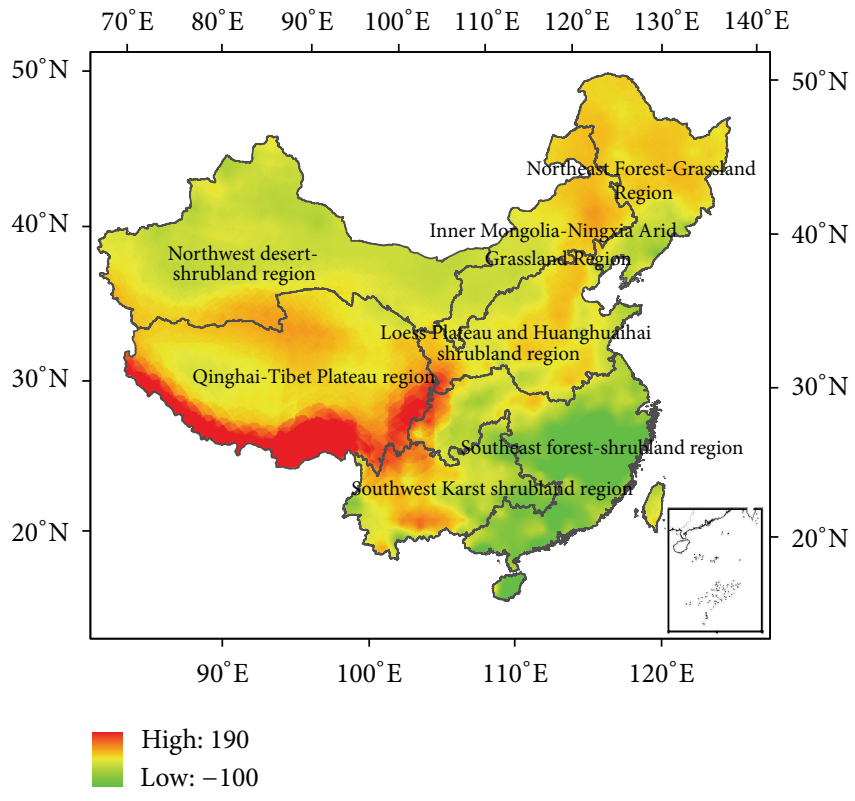

(b) Precipitation

FIGURE 5: The change of the temperature and precipitation using CMIP5 GCM from 2010 to 2050.

import and export trade and consumption will increase gradually. According to the trends of China's beef consumption, it can be deduced that with the improvement of income level, the consumption of beef will continue to grow and people's living standards are bound to rise to a new level. The forecast results indicated that the demand for beef will reach 9.8 million tons in 2020 and increase to 15.38 million tons in 2050. The increase of beef consumption would put more pressure on the grassland productivity. The result indicates that the annual average temperature of Qinghai-Tibet Plateau and northwest part of China will increase by $1.3^{\circ} \mathrm{C}$ in the future 40 years. Besides, the annual precipitation will show a slight increasing trend, with an increment of $100 \mathrm{~mm}$ in the future 40 years (Figure 5). In addition, the simulation result indicates that the grassland ecological-economic regions in China will become warmer and wetter in the future, which is favorable to the increase of grassland productivity. According to the simulation with the CCSM model, the change of the temperature and precipitation will make the grassland productivity in China increase by $8.3 \%-16.7 \%$ under the RCPs-PD scenarios. However, the grassland productivity would reduce greatly due to the decrease of moisture and the increase of the temperature and evaporation in the arid and semiarid regions of China during 2010-2050 under the RCPs scenarios.

\section{Conclusions}

This study analyzed the correlation between the grassland productivity and the climate change on the basis of the panel data at the national levels and assessed the contribution of climate to the change of grassland productivity at the regional level. The research also employs the climate change scenarios to analyze the pressure on the grassland productivity in the future. Despite some limitations due to the quality and spatial resolution of the data, the data are still helpful in assessing the impacts of the climate change on the grassland productivity. The data indicate that grassland is an important land use type in China, accounting for approximately $40 \%$ of the total land area of China. There is significant spatial variability of the grassland productivity in different grassland ecologicaleconomic regions. The result of the correlation analysis shows that the precipitation is the key limiting factor of the grassland productivity in the Inner Mongolia-Ningxia arid grassland region and northwest desert-shrub land region. At the same time, we found the temperature is beneficial to the increase of grassland productivity in Qinghai-Tibet Plateau. The simulation result with the CCSM model indicates that the change of the temperature and precipitation will make the grassland productivity in China increase by $8.3 \%-16.7 \%$ during $2010-$ 2050 under the RCPs-PD scenarios. The experiments in this study have been done using the GCM production and more effects should be made in the future research to further reveal the relationship between the dynamical downscaled climate data and grassland productivity.

The sustainability of the grassland ecosystems is influenced by various factors such as the increasing demand of human for meat, increased cropland area and increasing land use intensity of the agricultural system. The spatial heterogeneity of the grassland productivity is well consistent with that of the stockbreeding productivity, indicating the importance of the grassland to stockbreeding in the pastoral area of China. The grassland productivity in the pastoral area is considerably lower than that in the farming-pastoral ecotone and agricultural area where there is high-intensity management and input. As the pastoral grasslands are usually 
located in the environmentally fragile regions where it is unsuited for intensive exploitation, the farmers, pastoralists, ecologists, policy makers, and economists all should look for a way to combine the grassland production and the grassland protection under the condition of land use change and climate change.

\section{Acknowledgments}

This research was supported by the National Basic Research Program of China (973 Program) (no. 2012CB95570001). Data supports from projects of the National Natural Science Foundation of China (no. 71225005) and the Exploratory Forefront Project for the Strategic Science Plan in IGSNRR, CAS, are also appreciated.

\section{References}

[1] L. Kang, X. Han, Z. Zhang, and O. J. Sun, "Grassland ecosystems in China: review of current knowledge and research advancement," Philosophical Transactions of the Royal Society B, vol. 362, no. 1482, pp. 997-1008, 2007.

[2] J. Z. Ren, Z. Z. Hu, J. Zhao et al., "A grassland classification system and its application in China," Rangeland Journal, vol. 30, no. 2, pp. 199-209, 2008 (Chinese).

[3] Oak Ridge National Laboratory, "Estimation of NPP for Grassland," http://daac.ornl.gov/cgi-bin/dsviewer.pl?ds_id=614.

[4] D. Baldocchi, "Global change: the grass response," Nature, vol. 476, no. 7359, pp. 160-161, 2011.

[5] J. Qi, J. Chen, S. Wan, and L. Ai, "Understanding the coupled natural and human systems in Dryland East Asia," Environmental Research Letters, vol. 7, no. 1, Article ID 015202, 2012.

[6] IPCC, The Physical Science Basis. Contribution of Working Group I to the Fourth Assessment Report of the Intergovernmental Panel on Climate Change, Intergovernmental Panel on Climate Change, Geneva, Switzerland, 2007.

[7] M. Jongen, J. S. Pereira, L. M. I. Aires, and C. A. Pio, “The effects of drought and timing of precipitation on the inter-annual variation in ecosystem-atmosphere exchange in a Mediterranean grassland," Agricultural and Forest Meteorology, vol. 151, no. 5, pp. 595-606, 2011.

[8] S. Niu, M. Wu, Y. Han, J. Xia, L. Li, and S. Wan, "Water-mediated responses of ecosystem carbon fluxes to climatic change in a temperate steppe," New Phytologist, vol. 177, no. 1, pp. 209-219, 2008.

[9] Y. Bai, X. Han, J. Wu, Z. Chen, and L. Li, "Ecosystem stability and compensatory effects in the Inner Mongolia grassland," Nature, vol. 431, no. 7005, pp. 181-184, 2004.

[10] K. Klumpp, T. Tallec, N. Guix, and J. Soussana, "Long-term impacts of agricultural practices and climatic variability on carbon storage in a permanent pasture," Global Change Biology, vol. 17, no. 12, pp. 3534-3545, 2011.

[11] O. E. Sala, W. J. Parton, L. A. Joyce, and W. K. Lauenroth, "Primary production of the central grassland region of the United States," Ecology, vol. 69, no. 1, pp. 40-45, 1988.

[12] X. Zhang, J. Dai, and Q. Ge, "Variation in vegetation greenness in spring across eastern China during 1982-2006," Journal of Geographical Sciences, vol. 23, no. 1, pp. 1-12, 2013.

[13] J. Chen, U. K. T. Paw, S. L. Ustin et al., "Net ecosystem exchanges of carbon, water, and energy in young and old-growth douglasfir forests," Ecosystems, vol. 7, no. 5, pp. 534-544, 2004.
[14] T. Kato and Y. Tang, "Spatial variability and major controlling factors of $\mathrm{CO}_{2}$ sink strength in Asian terrestrial ecosystems: evidence from eddy covariance data," Global Change Biology, vol. 14, no. 10, pp. 2333-2348, 2008.

[15] C. Yi, D. Ricciuto, R. Li et al., "Climate control of terrestrial carbon exchange across biomes and continents," Environmental Research Letters, vol. 5, no. 3, pp. 1-10, 2010.

[16] X. Xu and K. Li, "Biomass carbon sequestration by planted forests in China," Chinese Geographical Science, vol. 20, no. 4, pp. 289-297, 2010.

[17] A. Prescher, T. Grünwald, and C. Bernhofer, "Land use regulates carbon budgets in eastern Germany: from NEE to NBP," Agricultural and Forest Meteorology, vol. 150, no. 7-8, pp. 1016$1025,2010$.

[18] M. J. Zeeman, R. Hiller, A. K. Gilgen et al., "Management and climate impacts on net $\mathrm{CO}_{2}$ fluxes and carbon budgets of three grasslands along an elevational gradient in Switzerland," Agricultural and Forest Meteorology, vol. 150, no. 4, pp. 519-530, 2010.

[19] S. L. Niu, Y. Q. Luo, S. F. Fei et al., "Seasonal hysteresis of net ecosystem exchange in response to temperature change: patterns and causes," Global Change Biology, vol. 17, no. 10, pp. 3102-3114, 2011.

[20] Y. Wang and G. Zhou, "Responses of temporal dynamics of aboveground net primary productivity of Leymus chinensis community to precipitation fluctuation in Inner Mongolia," Acta Ecologica Sinica, vol. 24, no. 6, pp. 1140-1145, 2004.

[21] G. Fischer, Y. Ermoliev, M. Keyzer, and C. Rosenzweig, "Simulating the socio-economic and biogeophysical driving forces of land-use and land-cover change: the IIASA land-use change model," WP-96-010, International Institute for Applied Systems Analysis (IIASA), Laxenburg, Austria, 1996.

[22] J. Ren, Z. Hu, Z. Zhang, F. Hou, and Q. Chen, "A preliminary discussion on grassland ecological-economic regions in China," Acta Prataculturae Sinica, vol. 8, pp. 12-22, 1999.

[23] H. Sun, Ecosystems of China, Science Press, Beijing, China, 2005.

[24] H. Yu, J. Xu, E. Okuto, and E. Luedeling, "Seasonal response of grasslands to climate change on the Tibetan Plateau," PLoS ONE, vol. 7, no. 11, Article ID e49230, 2012.

[25] J. Ni, "Plant functional types and climate along a precipitation gradient in temperate grasslands, North-East China and SouthEast Mongolia," Journal of Arid Environments, vol. 53, no. 4, pp. 501-516, 2003.

[26] Z. Su, X. Cheng, F. Huang, and S. Yang, "Response of grassland productivity to climate change in farming-pasturing interlaced area of Ningxia," Journal of Desert Research, vol. 27, no. 3, pp. 430-435, 2007.

[27] J. Liu, M. Liu, D. Zhuang, Z. Zhang, and X. Deng, “The spatial pattern analysis of land use change of China," Science in China $D$, vol. 32, no. 13, pp. 1031-1040, 2002 (Chinese).

[28] J. Liu, M. Liu, D. Zhuang, Z. Zhang, and X. Deng, "Study on spatial pattern of land-use change in China during 1995-2000," Science in China D, vol. 46, no. 4, pp. 373-384, 2003.

[29] S. W. Running, R. R. Nemani, F. A. Heinsch, M. Zhao, M. Reeves, and H. Hashimoto, "A continuous satellite-derived measure of global terrestrial primary production," BioScience, vol. 54, no. 6, pp. 547-560, 2004.

[30] C. J. Tucker, J. E. Pinzon, M. E. Brown et al., "An extended AVHRR 8-km NDVI dataset compatible with MODIS and SPOT vegetation NDVI data," International Journal of Remote Sensing, vol. 26, no. 20, pp. 4485-4498, 2005. 
[31] J. Jin, S. Lu, S. L. Norman, and L. Miller, "Impact of land use change on the local climate over the Tibetan Plateau," Advances in Meteorology, vol. 2010, Article ID 837480, 6 pages, 2010.

[32] D. King, K. Richards, and S. Tyldesley, International Climate Change Negotiations: Key Lessons and Next Steps, Smith School of Enterprise and the Environment, University of Oxford, Oxford, UK, 2011.

[33] R. H. Moss, J. A. Edmonds, K. A. Hibbard et al., "The next generation of scenarios for climate change research and assessment," Nature, vol. 463, no. 7282, pp. 747-756, 2010. 

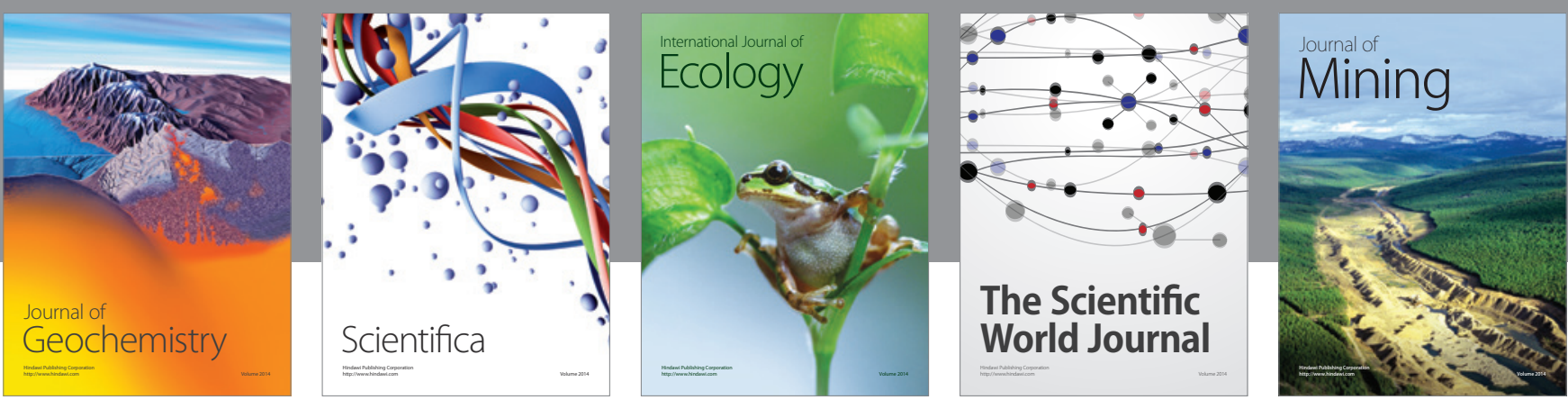

The Scientific World Journal
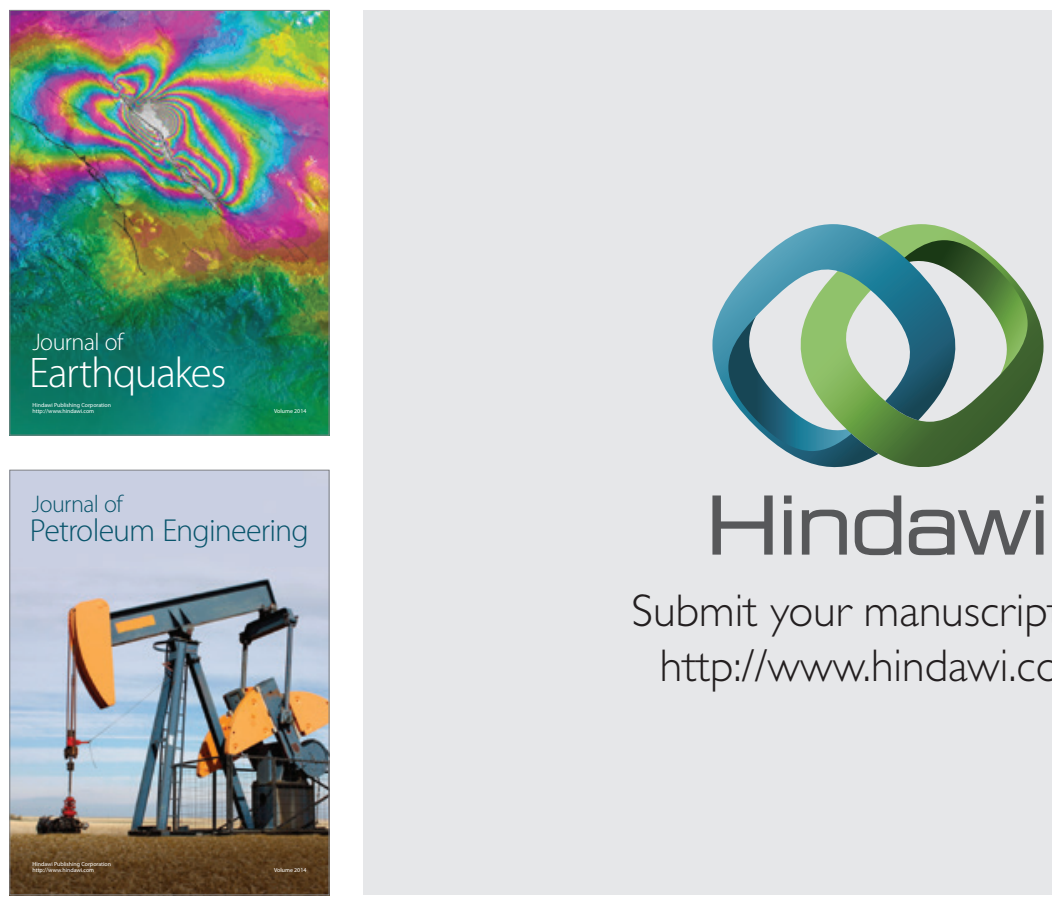

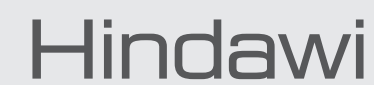

Submit your manuscripts at

http://www.hindawi.com
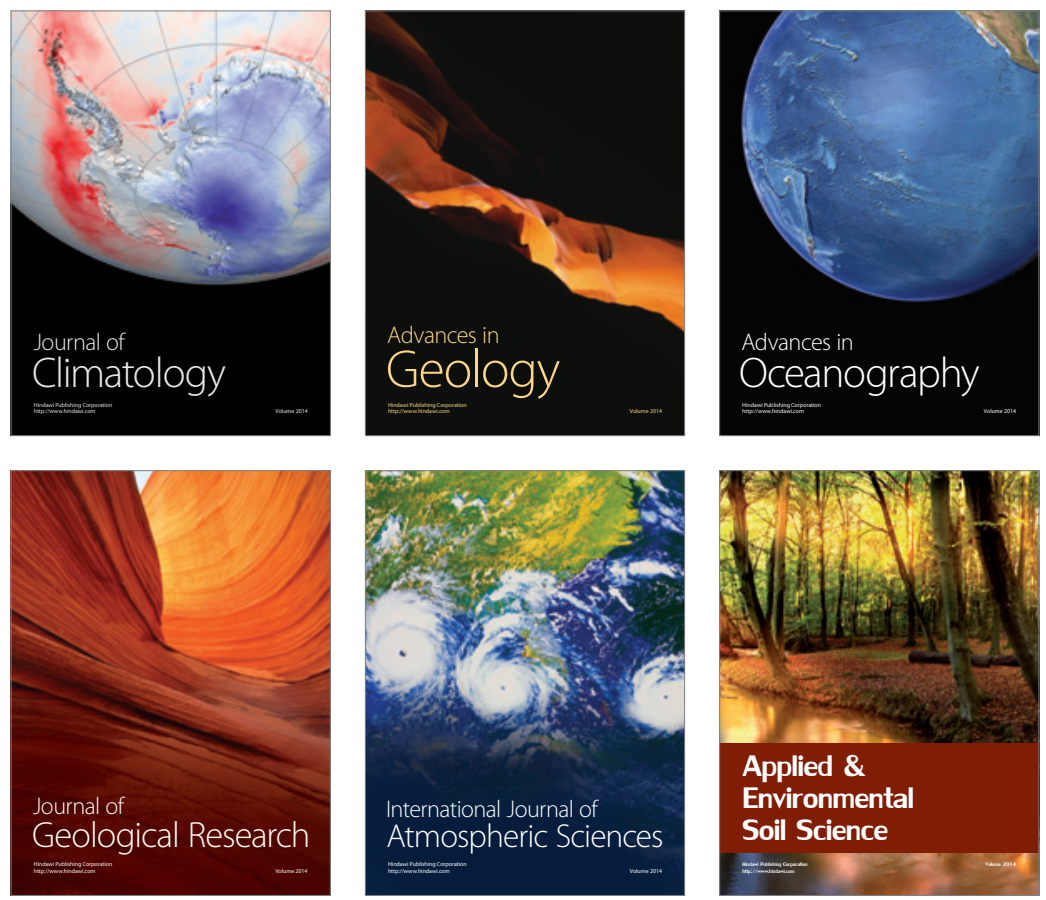
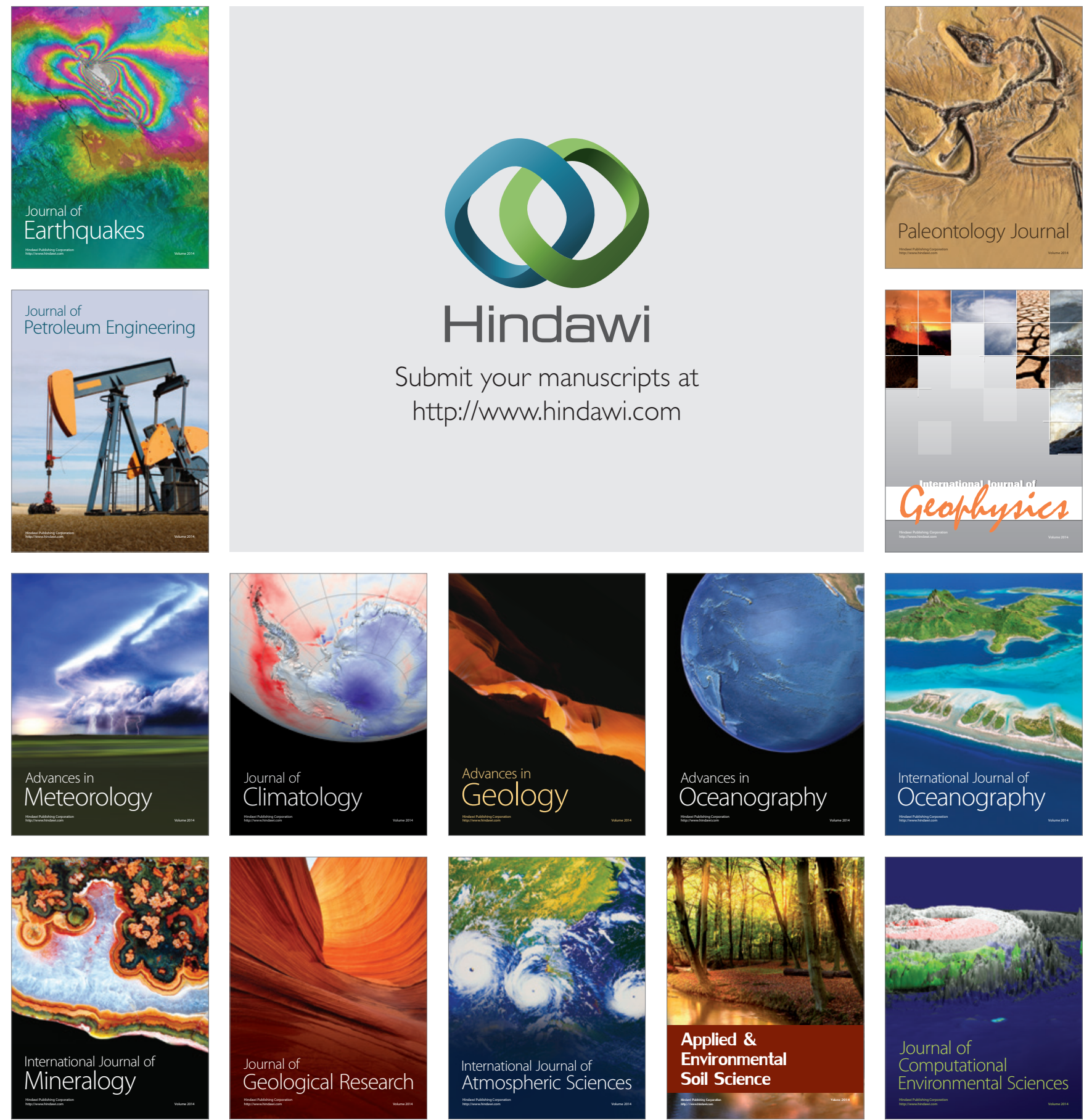